\title{
Thrombotic thrombocytopenic purpura/haemolytic uraemic syndrome associated with clopidogrel: report of two new cases
}

\author{
F Andersohn, F G Hagmann, E Garbe
}

Heart 2004;90:e57 (http://www.heartinl.com/cgi/content/full/90/9/e57). doi: 10.1136/hrt.2004.039214

Clopidogrel has been reported to be safe and effective in reducing vascular events. Nevertheless, there is growing evidence that clopidogrel may cause thrombotic thrombocytopenic purpura/haemolytic uraemic syndrome (TTP/HUS). This association has been debated, since in several cases alternative causes could not be excluded. Two new cases of TTP/HUS associated with clopidogrel are reported here. After discontinuation of clopidogrel and treatment with plasma exchange, both patients had a complete and sustained recovery from TTP/HUS. These cases corroborate previous observations that clopidogrel may indeed be a rare cause of TTP/HUS.

\footnotetext{
C
} lopidogrel, an antiplatelet drug, has largely replaced ticlopidine as the agent of choice for patients undergoing arterial stenting because clopidogrel has a better side effect profile. Treatment with ticlopidine leads to severe neutropenia in about $1 \%$ of patients ${ }^{12}$ and to the development of thrombotic thrombocytopenic purpura/haemolytic uraemic syndrome (TTP/HUS) in about $0.02 \%$ of patients. ${ }^{3}$. Clopidogrel's safety and efficacy were studied in the large CAPRIE (clopidogrel versus aspirin in patients at risk of ischaemic events) trial, ${ }^{4}$ in which the incidence of severe neutropenia was lower and TTP/HUS did not occur. Recently, 11 cases of clopidogrel associated TTP/HUS have been reported in an active surveillance study, ${ }^{5}$ but it has been debated whether these cases present enough evidence for causality. ${ }^{6}$ Here we report two new cases of clopidogrel associated TTP/HUS.

\section{CASE REPORTS}

\section{Case 1}

A 76 year old man was admitted to hospital because of a pathological blood count and increasing somnolence. Laboratory testing showed the following abnormalities: haemoglobin $(7.3 \mathrm{~g} / \mathrm{dl})$, platelet count $\left(4 \times 10^{9} / 1\right)$, lactate dehydrogenase (1120 IU/l), total bilirubin $(27.6 \mu \mathrm{mol} / \mathrm{l})$, haptoglobin $(<0.9 \mu \mathrm{mol} / \mathrm{l})$, and a slight red cell schistocytosis in the peripheral blood smear. The direct antiglobulin test was negative. The patient was taking long term medication with methotrexate and ibuprofen for rheumatoid arthritis and timolol eye drops for glaucoma (fig 1). Nine days before admission the patient had been placed on a new regimen of pantoprazole for erosive gastritis, ramipril and torasemide for hypertension and cardiac insufficiency, and clopidogrel ( $75 \mathrm{mg} /$ day) because of occlusion of both arteriae carotis internae. At that time, his haemoglobin concentration was $10.8 \mathrm{~g} / \mathrm{dl}$. Three days before admission, the patient had started ambulatory treatment with nadroparin for a deep vein thrombosis of the right leg. In hospital, TTP was diagnosed and methotrexate, clopidogrel, pantoprazole, and torasemide were stopped. Daily plasmapheresis was started and the patient received an average exchange of $4180 \mathrm{ml}$ ( 19 units) of fresh frozen plasma a day. Eleven days after admission, the platelet count had normalised. Plasmapheresis was stopped two days later. Before the patient was discharged from the hospital, treatment with pantoprazole and torasemide was replaced by esomeprazole and furosemide (frusemide). Treatment with methotrexate and clopidogrel was not resumed and the patient had no further relapse of TTP/HUS during the next 23 months.

\section{Case 2}

A 43 year old man was admitted to the hospital emergency room for acute angina pectoris. A myocardial infarction was excluded but routine laboratory testing showed the following abnormal values: platelet count $\left(23 \times 10^{9} / 1\right)$, white blood cell count $\left(14 \times 10^{9} / \mathrm{l}\right)$, total bilirubin $(145.4 \mu \mathrm{mol} / \mathrm{l})$, and creatinine $(168 \mu \mathrm{mol} / \mathrm{l})$. On the second day after hospital admission, the patient's platelet count further decreased to $13 \times 10^{9} / \mathrm{l}$, total bilirubin increased to $197.0 \mu \mathrm{mol} / \mathrm{l}$, and creatinine increased to $203 \mu \mathrm{mol} / \mathrm{l}$. Lactate dehydrogenase was $2970 \mathrm{IU} / \mathrm{l}$, haemoglobin $13.9 \mathrm{~g} / \mathrm{dl}$, and free haemoglobin $75 \mathrm{mg} / \mathrm{dl}$ (normal range $<10 \mathrm{mg} / \mathrm{dl}$ ). His peripheral blood smear showed red blood cell fragmentation. The direct antiglobulin test was negative. On the third day after hospital admission, his haemoglobin further decreased to $7.8 \mathrm{~g} / \mathrm{dl}$. Three weeks before hospital admission, the patient had been started on a regimen with clopidogrel $(75 \mathrm{mg} /$ day), dalteparin, metoprolol, acetylsalicylic acid, molsidomine, and glyceryl trinitrate spray for unstable angina pectoris, and was waiting for scheduled cardiac catheterisation with angioplasty (fig 2). In hospital, HUS was diagnosed. All drugs were stopped and the patient was treated with daily plasmapheresis with an average exchange of $2520 \mathrm{ml}$ (12 units) fresh frozen plasma for five days. Additionally, methylprednisolone was administered in tapering doses. Four days after hospital admission, the patient had a posterior myocardial infarction. Under treatment with plasmapheresis and glucocorticoids, the platelet count gradually increased and returned to normal on day 10. All drugs were reintroduced except clopidogrel and dalteparin. The patient has had no relapse of TTP/HUS and six months after discharge his blood count was still normal.

\section{DISCUSSION}

The causality between clopidogrel intake and TTP has been debated recently. ${ }^{6}$ In some case reports other drugs could not

Abbreviations: CAPRIE, clopidogrel versus aspirin in patients at risk of ischaemic events; HUS, haemolytic uraemic syndrome; TTP, thrombotic thrombocytopenic purpura 

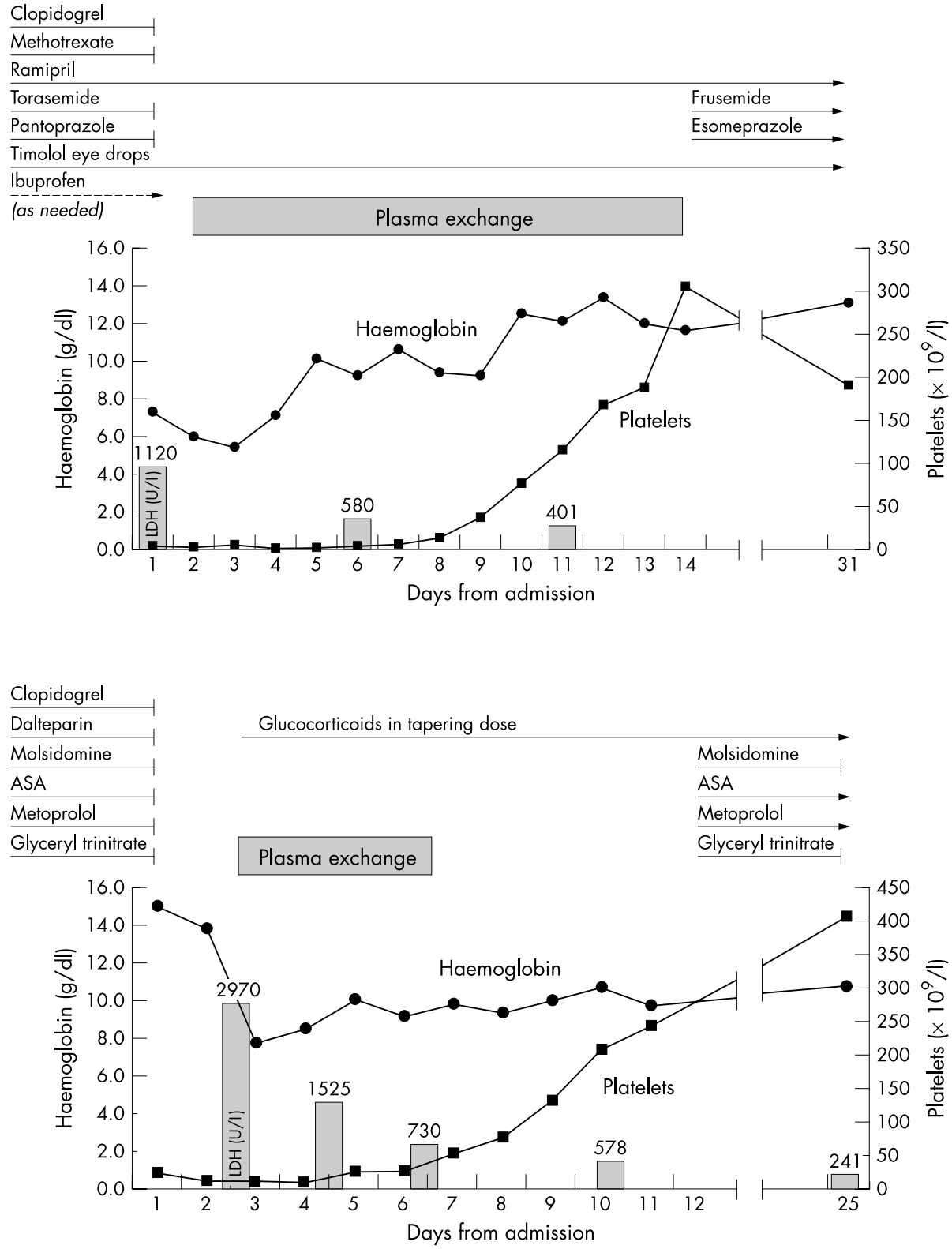

Figure 1 Case 1. Medication and course of platelet, haemoglobin, and lactate dehydrogenase (LDH) concentrations.
Figure 2 Case 2. Medication and course of platelets, haemoglobin, and LDH. ASA, acetylsalicylic acid (aspirin). be ruled out as an alternative cause. ${ }^{7}$ In others, either TTP/ HUS recurred without repeated intake of clopidogrel ${ }^{5}$ or an underlying disease causing TTP/HUS could not be excluded. ${ }^{8}$ In a single case, it may be difficult or even impossible to establish a definitive relation between drug intake and occurrence of a disease, since re-exposure is usually not feasible for ethical reasons. Causality assessment would therefore be based on other criteria such as a plausible time course between the initiation of clopidogrel treatment and the occurrence of TTP/HUS; complete and sustained recovery from TTP/HUS after discontinuation of clopidogrel; reintroduction of other drugs without reoccurrence of TTP/HUS; and exclusion of other causes of TTP/HUS. The treatment duration with clopidogrel was nine days in case 1 and three weeks in case 2 before diagnosis of TTP/HUS. In the published case series by Bennett and colleagues, ${ }^{5}$ most cases of TTP related to clopidogrel occurred during the first two weeks of treatment and one case after 11 months of clopidogrel. ${ }^{5}$

Both our patients had a sustained recovery from TTP/HUS after discontinuation of clopidogrel for at least six and 23 months, respectively. Whereas the first patient had a number of different diseases, the second had no other underlying diseases except coronary heart disease and systemic hypertension. Moreover, the second patient resumed all other drugs except clopidogrel and dalteparin without relapse of TTP/HUS. Since, to our knowledge, neither dalteparin nor any other low molecular weight heparin has ever been reported to cause TTP/HUS, an association with clopidogrel seems probable in this case. In summary, our cases corroborate the observation that clopidogrel may indeed be a cause of drug induced TTP/HUS.

\section{ACKNOWLEDGEMENTS}

Case data were collected within the study Berlin case control surveillance of serious blood dyscrasias, which is supported by a grant from the Federal Institute for Drugs and Medical Devices, Bonn, Germany.

\section{Authors' affiliations}

F Andersohn, E Garbe, Institute of Clinical Pharmacology, CharitéUniversity Medicine, Berlin, Germany 
F G Hagmann, Department of Internal Medicine I, Westpfalz-Klinikum, Kaiserslautern, Germany

Correspondence to: $\mathrm{Dr}$ med $\mathrm{F}$ Andersohn, Institute of Clinical Pharmacology, Charité-University Medicine Berlin, Campus Charité Mitte, Schumannstrasse 20/21, 10117 Berlin, Germany;

frank.andersohn@charite.de

Accepted 28 April 2004

\section{REFERENCES}

1 Hass WK, Easton JD, Adams HP Jr, et al. A randomized trial comparing ticlopidine hydrochloride with aspirin for the prevention of stroke in high-risk patients. Ticlopidine aspirin stroke study group. N Engl J Med 1989;321:501-7.

2 Berger PB, Bell MR, Grill DE, et al. Frequency of adverse clinical events in the 12 months following successful intracoronary stent placement in patients treated with aspirin and ticlopidine (without warfarin). Am J Cardiol 1998:81:713-8.

3 Steinhubl SR, Tan WA, Foody JM, et al. Incidence and clinical course of thrombotic thrombocytopenic purpura due to ticlopidine following coronary stenting. EPISTENT investigators. Evaluation of platelet $\mathrm{llb} / \mathrm{llla}$ inhibitor for stenting. JAMA 1999:281:806-10

4 CAPRIE Steering Committee. A randomised, blinded, trial of clopidogrel versus aspirin in patients at risk of ischaemic events (CAPRIE). Lancet 1996;348:1329-39.

5 Bennett CL, Connors JM, Carwile JM, et al. Thrombotic thrombocytopenic purpura associated with clopidogrel. N Engl J Med 2000;342: 1773-7.

6 Maihail NS, Lichtin AE. Clopidogrel and thrombotic thrombocytopenic purpura: no clear case for causality. Cleve Clin J Med 2003;70:466-70

7 Carwile JM, Laber DA, Soltero ER, et al. Thrombotic thrombocytopenic purpura occurring after exposure to clopidogrel. Blood 1999;94:78b.

8 Nara W, Ashley I, Rosner F. Thrombotic thrombocytopenic purpura associated with clopidogrel administration: case report and brief review. Am J Med Sci $2001 ; 322: 170-2$ 